\title{
BMJ open Variation in severe maternal morbidity according to socioeconomic position: a UK national case-control study
}

\author{
Anthea Lindquist, ${ }^{1,2}$ Marian Knight,, ${ }^{1,3}$ Jennifer J Kurinczuk ${ }^{1,3}$
}

To cite: Lindquist $A$, Knight M, Kurinczuk JJ. Variation in severe maternal morbidity according to socioeconomic position: a UK national case-control study. BMJ Open 2013;3: e002742. doi:10.1136/ bmjopen-2013-002742

- Prepublication history for this paper is available online. To view these files please visit the journal online (http://dx.doi.org/10.1136/ bmjopen-2013-002742).

Received 23 February 2013 Revised 1 May 2013 Accepted 14 May 2013

This final article is available for use under the terms of the Creative Commons Attribution Non-Commercial 2.0 Licence; see http://bmjopen.bmj.com

\footnotetext{
${ }^{1}$ National Perinatal Epidemiology Unit, University of Oxford, Oxford, UK ${ }^{2}$ Department of Obstetrics and Gynaecology, Monash University, Melbourne, Victoria, Australia ${ }^{3}$ Department of Public Health, University of Oxford, Oxford, UK
}

Correspondence to Professor Marian Knight; marian.knight@npeu.ox.ac.uk

\begin{abstract}
Objectives: This study aimed to explore the independent association between socioeconomic position, defined by occupation, and severe maternal morbidity among women in the UK.

Design: Case-control study.

Setting: The analysis was conducted as a case-control analysis, using data from a series of studies of direct causes of severe maternal morbidity undertaken through the UK Obstetric Surveillance System (UKOSS), with data collected throughout all consultant-let obstetric units in the UK.
\end{abstract}

Participants: The analysis included 1144 cases and 2256 comparison women (controls). UKOSS studies from which data on case women were obtained included amniotic fluid embolism, acute fatty liver of pregnancy, eclampsia, peripartum hysterectomy, therapies for peripartum haemorrhage and uterine rupture.

Primary outcome measure: Odds of severe maternal morbidity by socioeconomic group, independent of ethnicity, maternal age, smoking, pre-existing medical condition, body mass index (BMI), multiple pregnancy and past pregnancy complications. Occupation was used to classify different socioeconomic groups.

Secondary outcome measure: Odds of morbidity related to ethnic group, maternal age, smoking, pre-existing medical condition, BMI, multiple pregnancy and past pregnancy complications.

Results: Across the socioeconomic groups, compared with the 'managerial/professional' group, adjusted ORs were $1.17(95 \% \mathrm{Cl} 0.94$ to 1.45$)$ for the 'intermediate group', 1.16 (95\% $\mathrm{Cl} 0.93$ to 1.45$)$ for 'routine/manual', $1.22(95 \% \mathrm{Cl} 0.92$ to 1.61$)$ for 'unemployed' women and $1.51(95 \% \mathrm{Cl} 1.18$ to 1.94$)$ for women with missing socioeconomic information. Women of nonwhite ethnicity, older maternal age ( $\geq 35$ years), $\mathrm{BMI} \geq 25 \mathrm{~kg} / \mathrm{m}^{2}$ and those with pre-existing medical condition/s, multiple pregnancy or past pregnancy complications were shown to have a significantly increased odds of severe maternal morbidity.

Conclusions: This study suggests that socioeconomic position may be independently associated with an increased risk of severe maternal morbidity, although the observed association was not statistically significant. Further research is warranted to confirm this and investigate why this association might exist in a country where healthcare is universal and free at the point of access.

\section{ARTICLE SUMMARY}

\section{Article focus}

- To explore the relationship between socioeconomic position, defined by occupation, and severe maternal morbidity using data obtained from a series of the UK Obstetric Surveillance System studies.

- To estimate the risk of severe morbidity by socioeconomic group, independent of ethnicity, maternal age, smoking, pre-existing medical condition, body mass index (BMI), multiple pregnancy and past pregnancy complications.

Key messages

- The results suggested that women from the lowest socioeconomic group are 1.22 times $(95 \% \mathrm{Cl} 0.92$ to 1.61$)$ more likely than women from the highest group to experience severe maternal morbidity.

- The results also showed that other risk factors for severe maternal morbidity include non-white ethnicity, older maternal age ( $\geq 35$ years), BMI $\geq 25 \mathrm{~kg} / \mathrm{m}^{2}$, pre-existing medical condition $/ \mathrm{s}$, multiple pregnancy or previous pregnancy complications.

Strengths and limitations of this study

- Study strengths include the robust case ascertainment, minimisation of sampling bias through collection of data from all consultant-led obstetric units in the UK and the clear definition of severe maternal morbidity.

- Limitations relate to the data available to define socioeconomic position and the application of the findings to other non-UK setting.

\section{INTRODUCTION}

Maternal morbidity is of major public health concern with some estimates suggesting that as many as 10 million women worldwide suffer from pregnancy-related complications each year. ${ }^{1}$ In countries where maternal deaths are infrequent, the information that mortality audits provide cannot be generalised readily across the general population of pregnant women, nor can it necessarily accurately predict which women are at increased risk of 
adverse outcomes. ${ }^{2}$ In these circumstances, additional focus on maternal morbidity is now widely recognised as a robust approach in improving maternal health and the quality of healthcare provision. $^{3-6}$

Identifying high-risk women is imperative to prevent adverse outcomes, since it allows more intensive clinical management to be directed towards these women and is the fundamental purpose of antenatal care. Extensive research has demonstrated convincing links between severe maternal morbidity and advanced maternal age, pre-existing medical conditions and obesity. ${ }^{1} 78$ However, these factors are unable to explain entirely the differences in maternal morbidity found between different populations of women both within and between countries. Other evidence suggests that ethnicity and social disadvantage may have a significant role to play, with UK data suggesting that women from ethnic minority groups and from socially disadvantaged groups are more likely to experience severe maternal morbidity than white women, and also to be at higher risk of dying from specific maternal morbidities. ${ }^{9-11}$ However, as highlighted by several studies exploring ethnic differences in maternal health, it is unclear whether ethnicity itself is directly related to poor outcomes or, more likely, whether it is a marker for factors such as low socioeconomic position and lower levels of education. ${ }^{12}$ As minority ethnic groups are often disproportionately represented in lower socioeconomic groups, results attributed to ethnic differences are likely to be confounded by socioeconomic differences. ${ }^{13}$ The aim of the analysis reported here was to explore whether there is an independent risk of severe maternal morbidity associated with socioeconomic position in the UK.

\section{METHODS}

\section{Data collection and definitions}

A case-control analysis was performed using data derived from a series of UK-wide studies of direct causes of maternal morbidity undertaken through the UK Obstetric Surveillance System (UKOSS). ${ }^{14}$ These studies were of amniotic fluid embolism, acute fatty liver of pregnancy, eclampsia, peripartum hysterectomy, therapies for peripartum haemorrhage and uterine rupture. ${ }^{15-21}$ For the purpose of this analysis, these cases are collectively referred to as 'severe maternal morbidity' (table 1).

The UKOSS methodology used to carry out a rolling programme of studies has been described in detail elsewhere. ${ }^{14}$ In brief, monthly mailing of notification cards to all obstetric-led maternity units in the UK enables the identification of all cases under study. Data collection forms despatched in response to a case notification are used by the clinician responsible for care to report deidentified information from the woman's medical notes. Follow-up of non-responders maximises the completeness of data collection and confirms denominator numbers for incidence estimates.

For many of the UKOSS studies, data about a representative sample of women without the specific condition under study were obtained by collecting information on the two women delivering immediately prior to each case in the same obstetric unit; these were defined as controls. The same information was collected about the controls as for case women. Data were thus available for analysis on 1144 cases of severe maternal morbidity and 2256 controls.

Maternal occupation was used to classify cases and controls by socioeconomic group, where this was not available her husband's/partner's occupation was used. Using the National Statistics Socio-Economic Classification (NS-SEC), ${ }^{22}$ occupation was coded into three categories plus an additional group for unemployed women.

\section{Statistical analysis}

All analyses were carried out using STATA V.11.0. Following univariable analysis multivariable unconditional logistic regression was used to examine the independent relationship between socioeconomic position and severe maternal morbidity and to generate adjusted ORs (aORs) with their 95\% CIs. Owing to the high proportion and distribution of missing data for some variables, particularly for socioeconomic position (table 2), 'missing' was included as a separate group for each categorical variable.

Variables likely to confound the relationship between socioeconomic position and severe maternal morbidity were identified a priori based on evidence from the published literature and the results of univariable analysis. These included ethnicity, maternal age, smoking, preexisting medical conditions and body mass index (BMI). ${ }^{1} 710 \quad 23-36$ Other variables included in the analysis as possible confounders were parity, multiple pregnancy and past pregnancy complications.

Model building using unconditional logistic regression proceeded by the inclusion of severe maternal morbidity (outcome) and socioeconomic position, with each of the potential confounders added in turn one-by-one. The individual effect of each variable on the fit of the data was assessed using the likelihood ratio test. The variables with a priori evidence of effect were included in the final model. Of the additional three variables examined (parity, multiple pregnancy and past pregnancy conditions), only those demonstrating a statistically significant effect $(p<0.05)$ on the fit of the data were retained; parity was thus excluded.

Age, included as a continuous variable, was tested for departure from linearity; the results are for ease of presentation, shown as categorical. BMI was included as a categorical variable due to the high proportion of missing data and the concern that by including it as continuous, women with missing data would be excluded. There was no evidence of a significant interaction between socioeconomic position and any of the other variables included in the final model $(\mathrm{p}<0.01)$.

Sensitivity analyses were conducted to explore the effect of missing data for socioeconomic position and BMI. The final multivariable regression model was rerun 
Table 1 Criteria used to define cases of severe maternal morbidity used in the UKOSS studies included in the analysis

\section{Condition}

Amniotic fluid embolism

Acute fatty liver of pregnancy

Eclampsia

Peripartum hysterectomy

Therapies for major peripartum haemorrhage

Uterine rupture

\section{Definition}

EITHER a clinical diagnosis of AFE (acute hypotension or cardiac arrest, acute hypoxia or coagulopathy in the absence of any other potential explanation for the symptoms and signs observed)

OR a pathological diagnosis (presence of fetal squames or hair in the lungs)

EITHER AFLP confirmed by biopsy or postmortem examination

OR a clinician has made a diagnosis of AFLP with signs and symptoms consistent with AFLP

The occurrence of convulsions during pregnancy or in the first 10 days postpartum, together with at least two of the following features within $24 \mathrm{~h}$ after the convulsions:

(1) Hypertension (a booking diastolic pressure of $<90 \mathrm{~mm} \mathrm{Hg}$, a maximum diastolic of $\geq 90 \mathrm{~mm} \mathrm{Hg}$ and a diastolic increment of $\geq 25 \mathrm{~mm} \mathrm{Hg}$ )

(2) Proteinuria (at least+protein in a random urine sample or $\geq 0.3 \mathrm{~g}$ in a 24 h collection)

(3) Thrombocytopenia (platelet count of $<100 \times 10^{9} / \mathrm{L}$ )

(4) An increased plasma alanine aminotransferase (ALT) concentration ( $\geq 42 \mathrm{IU} / \mathrm{L}$ ) or an increased plasma aspartate transaminase aminotransferase (AST) concentration ( $\geq 42 \mathrm{IU} / \mathrm{L})$

Any woman giving birth to an infant and having a hysterectomy during the same clinical episode

All women in the UK treated therapeutically or prophylactically for major peripartum haemorrhage with:

EITHER Activated factor VIla

OR B-lynch suture or other brace suture

OR Arterial ligation or embolisation

Any woman in the UK identified as having a uterine rupture using the following definition:

A complete separation of the wall of the pregnant uterus, with or without expulsion of the fetus, involving rupture of the membranes at the site of the uterine rupture or extension into the uterine muscle separate from any previous scar, and endangering the life of the mother or fetus Excluded: any asymptomatic palpable or visualised defect (eg, dehiscence noted incidentally at caesarean delivery)
UKOSS study timeframe

01/02/2005$31 / 01 / 2010$

01/02/2005$30 / 04 / 2006$

$01 / 02 / 2005$ $29 / 02 / 2006$

$01 / 02 / 2005-$ $29 / 02 / 2006$

$01 / 09 / 2007-$ $30 / 09 / 2008$

01/04/2009 $30 / 04 / 2010$

AFE, amniotic fluid embolism; AFLP, acute fatty liver of pregnancy; UKOSS, UK Obstetric Surveillance System.

after redistributing missing values into the lowest and highest categories for each of these variables.

The findings demonstrated that the distribution and impact of missing data were substantial and that the pattern of missing data was unlikely to be 'missing at random'. The results of multivariable analysis were therefore likely to be biased by the high proportion and non-random pattern of missing data if the missing observations were not accounted for. Owing to the evidence against a 'missing at random' assumption, multiple imputation was not an appropriate solution to deal with the effects of missing data. We therefore included the missing data as a separate category for the relevant variables, treating them as 'proxy indicators' in the subsequent model-building processes.

\section{Study power}

The analysis included a fixed number of cases and controls derived from specified UKOSS studies. On the basis of 1144 cases and 2256 controls, and with a prevalence of $13 \%$ for the lowest (unemployed) socioeconomic group, the analysis had $80 \%$ power to detect as statistically significant $(\mathrm{p}<0.05)$ an odds of 1.32 or greater and $90 \%$ power to detect as statistically significant $(p<0.05)$ an odds of 1.37 or greater, for comparisons with the highest (managerial/professional) socioeconomic group.

\section{RESULTS}

The analysis included a total of 1144 cases of severe maternal morbidity and 2256 controls. Compared with the controls, cases were more likely to be older, multiparous, of non-white ethnicity, to have missing socioeconomic position and BMI information, to be non-smokers, to have a pre-existing medical condition, a history of past pregnancy complications and a multiple pregnancy in the index pregnancy (table 3 ). 
Table 2 Distribution of missing data for cases of severe maternal morbidity and controls

\begin{tabular}{lcc}
\hline & $\begin{array}{l}\text { Number of } \\
\text { cases with } \\
\text { missing } \\
\text { information } \\
\text { (\% of total } \\
\text { cases) }\end{array}$ & $\begin{array}{l}\text { Number of } \\
\text { controls with } \\
\text { missing } \\
\text { information } \\
\text { (\% of total } \\
\text { controls) }\end{array}$ \\
Variable & $193(16.9)$ & $303(13.4)$ \\
\hline Socioeconomic & $18(1.6)$ & $78(3.5)$ \\
group & $3(0.3)$ & $18(0.8)$ \\
Ethnicity & $28(2.5)$ & $61(2.7)$ \\
Age & $6(0.5)$ & $27(1.2)$ \\
Smoking & $128(11.2)$ & $219(9.7)$ \\
Pre-existing medical & $22(1.0)$ \\
condition(s) & $3(0.3)$ & $18(0.8)$ \\
Body mass index & $2(0.2)$ & $31(1.4)$ \\
Parity & $9(0.8)$ & \\
Multiple pregnancy & & \\
Past pregnancy & & \\
complication(s) & &
\end{tabular}

Following adjustment, compared with the controls, cases were 1.17 (95\% CI 0.94 to 1.45$)$ times more likely to be in the 'intermediate' socioeconomic group than the 'managerial/professional' group, 1.16 (95\% CI 0.93 to 1.45) times more likely to be in the 'routine/manual' group, 1.22 (95\% CI 0.92 to 1.61 ) times more likely to be unemployed, noting that these were not statistically significant increases. Cases were statistically significantly 1.51 (95\% CI 1.18 to 1.94$)$ times more likely to have missing socioeconomic information than controls. Compared with controls, cases were 1.77 (95\% CI 1.32 to 2.36) times more likely to be black than white, $1.57(95 \%$ CI 1.23 to 2.00 ) times more likely to be Asian and 1.50 (95\% CI 1.02 to 2.19) times more likely to be from another minority ethnic group, all statistically significant associations. The relationship between the odds severe maternal morbidity and maternal age was J-shaped with cases having significantly raised adjusted odds of being 30-34 years (aOR 1.33; 95\% CI 1.08 to 1.64 ) or $35+$ years (aOR 1.98; 95\% CI 1.60 to 2.45). After adjustment, cases had a non-significant $10 \%$ increase in the odds of having a BMI of 25 or over and a $24 \%$ increase in the odds of having missing BMI data which was similarly nonsignificant. Cases were significantly more likely than controls to have a history of pre-existing medical conditions (aOR $1.60 ; 95 \%$ CI 1.18 to 2.17 ), past pregnancy complications (aOR 1.58; 95\% CI 1.16 to 2.14 ) and to have a multiple pregnancy (aOR 3.54; 95\% CI 2.18 to 5.76 ).

\section{Sensitivity analysis}

Redistributing all the missing socioeconomic observations into the managerial/professional group reduced the aOR associated with unemployment to 1.02 (95\% CI 0.79 to 1.32 ), a non-significant association, whereas redistribution of all the missing socioeconomic observations into the unemployed group produced an aOR of 1.38 (95\% CI 1.11 to 1.72) associated with unemployment (table 4), a statistically significant increase.

Rerunning the multivariable model including only those cases and controls with complete information for every variable generated an aOR of 1.31 (95\% CI 0.97 to 1.77) associated with unemployment, an aOR of 1.13 (95\% CI 0.89 to 1.43 ) for the routine/manual group and $1.19(95 \%$ CI 0.94 to 1.49$)$ for the intermediate group. These results are very similar to the estimates from the analysis using proxy indicators.

\section{DISCUSSION \\ Findings}

The results of this study suggest that there may be an independent association between socioeconomic position and severe maternal morbidity. We found that, compared with women from the highest managerial/ professional socioeconomic group, unemployed status was associated with a $22 \%$ increase in the odds of severe morbidity. However, this was not a statistically significant association and may therefore represent a chance finding. Women with missing socioeconomic information had a more than $50 \%$ increase in the odds of severe morbidity and this finding was unlikely to be due to chance. The women with missing socioeconomic information were clearly different in a range of characteristics than the women with complete information, and we hypothesised that these women were more likely to be unemployed. To explore what the impact of this might be in our analysis if this hypothesis were correct, we undertook a sensitivity analysis which suggested that if all the women with missing socioeconomic data were unemployed, the estimate of the odds of severe morbidity increased to $38 \%$; with a result unlikely to be due to chance. It is important to note, however, that as information about the covariates was obtained by an obstetrician knowing the outcome status of the women, the missing values and/or potential misclassification might be differential according to outcome. We are unable to assess any further whether our hypothesis about those with missing information is correct; nevertheless, we believe this potential association is worthy of further investigation among different populations and using different methodologies to determine whether it can be reproduced.

Despite universal healthcare which is free at the point of delivery, and significant investment in researching social inequalities in health in the $\mathrm{UK}$, socially marginalised groups continue to fare poorly as compared with more affluent sections of society, across a range of health outcomes including, as suggested by our analysis, maternal health. The reasons for the social gradient in maternal health in the UK have not yet been thoroughly explored. It is therefore unclear whether the observed potential association is as a result of differences in the underlying risk of disease, including, but not limited to, lifestyle factors, 
Table 3 Maternal characteristics associated with severe maternal morbidity

\begin{tabular}{|c|c|c|c|c|}
\hline Characteristic & $\begin{array}{l}\text { Cases } n=(\%) \\
N=1144\end{array}$ & $\begin{array}{l}\text { Controls } n=(\%) \\
\mathrm{N}=2256\end{array}$ & $\begin{array}{l}\text { Unadjusted OR } \\
(95 \% \mathrm{Cl})\end{array}$ & Adjusted* OR $(95 \% \mathrm{Cl})$ \\
\hline \multicolumn{5}{|l|}{ Socioeconomic group } \\
\hline Managerial/professional & $292(25.5)$ & $567(25.1)$ & 1.0 & 1.0 \\
\hline Intermediate & $244(21.3)$ & $482(21.4)$ & $0.98(0.80$ to 1.21$)$ & $1.17(0.94$ to 1.45$)$ \\
\hline Routine/manual & $273(28.7)$ & $595(26.4)$ & 0.89 (0.73 to 1.09$)$ & $1.16(0.93$ to 1.45$)$ \\
\hline Unemployed & $142(14.9)$ & 309 (13.7) & $0.89(0.70$ to 1.14$)$ & $1.22(0.92$ to 1.61$)$ \\
\hline Missing & 193 (16.9) & $303(13.4)$ & 1.24 (0.98 to 1.56$)$ & 1.51 (1.18 to 1.94$)$ \\
\hline \multicolumn{5}{|l|}{ Ethnic group } \\
\hline White & $827(72.3)$ & 1796 (79.6) & 1.0 & 1.0 \\
\hline Asian & 139 (12.2) & 197 (8.7) & 1.53 (1.22 to 1.93$)$ & 1.57 (1.23 to 2.00$)$ \\
\hline Black & $108(9.4)$ & $116(5.1)$ & 2.02 (1.54 to 2.66$)$ & 1.77 (1.32 to 2.36$)$ \\
\hline Other & $52(4.6)$ & $69(3.1)$ & 1.64 (1.13 to 2.37$)$ & 1.50 (1.02 to 2.19$)$ \\
\hline Missing & $18(1.6)$ & 78 (3.5) & $0.50(0.30$ to 0.84$)$ & 0.51 (0.28 to 0.91) \\
\hline \multicolumn{5}{|l|}{ Age } \\
\hline$<20$ & $56(4.9)$ & $139(6.2)$ & $0.98(0.70$ to 1.39$)$ & $1.08(0.75$ to 1.56$)$ \\
\hline $20-24$ & $127(11.1)$ & 449 (19.9) & 0.69 (0.54 to 0.89$)$ & 0.71 (0.55 to 0.92$)$ \\
\hline $25-29$ & 225 (19.7) & $549(24.3)$ & 1.0 & 1.0 \\
\hline $30-34$ & 341 (29.8) & $622(27.6)$ & 1.34 (1.09 to 1.64$)$ & 1.33 (1.08 to 1.64$)$ \\
\hline$\geq 35$ & 392 (34.3) & 479 (21.2) & 2.00 (1.63 to 2.45$)$ & 1.98 (1.60 to 2.45$)$ \\
\hline Missing & $3(0.3)$ & $18(0.8)$ & 0.41 (0.12 to 1.39$)$ & $2.66(0.22$ to 26.00$)$ \\
\hline \multicolumn{5}{|l|}{ Smoking status } \\
\hline Non-smokers & $899(78.6)$ & $1642(72.8)$ & 1.0 & 1.0 \\
\hline Smokers & 217 (19.0) & $553(24.5)$ & $0.72(0.60$ to 0.86$)$ & $0.89(0.73$ to 1.08$)$ \\
\hline Missing & $28(2.5)$ & 61 (2.7) & 0.84 (0.53 to 1.32$)$ & 0.95 (0.54 to 1.67) \\
\hline \multicolumn{5}{|l|}{ BMI $\left(\mathrm{kg} / \mathrm{m}^{2}\right)$} \\
\hline \multicolumn{5}{|l|}{ increase in BMI) } \\
\hline$<25$ & $513(44.8)$ & 1121 (49.7) & 1.0 & 1.0 \\
\hline $25-29.9$ & 297 (26.0) & 545 (24.2) & 1.19 (1.00 to 1.42$)$ & $1.10(0.92$ to 1.32$)$ \\
\hline$\geq 30$ & $206(18.0)$ & $371(16.5)$ & 1.21 (0.99 to 1.48$)$ & 1.09 (0.88 to 1.34$)$ \\
\hline Missing & $128(11.2)$ & $219(9.7)$ & 1.28 (1.00 to 1.63$)$ & 1.24 (0.95 to 1.61$)$ \\
\hline \multicolumn{5}{|l|}{$\begin{array}{l}\text { Coexisting medical } \\
\text { conditions } \dagger\end{array}$} \\
\hline No & $1045(91.4)$ & $2126(94.2)$ & 1.0 & 1.0 \\
\hline Yes & $93(8.1)$ & 103 (4.6) & 1.84 (1.38 to 2.46$)$ & 1.60 (1.18 to 2.17$)$ \\
\hline Missing & $6(0.5)$ & 27 (1.2) & $0.45(1.18$ to 1.10$)$ & $0.76(0.17$ to 3.41$)$ \\
\hline \multicolumn{5}{|l|}{ Parity } \\
\hline Nulliparous & $403(35.2)$ & $984(43.6)$ & 1.0 & $\begin{array}{l}\text { No significant effect on fit of } \\
\text { model (excluded) }\end{array}$ \\
\hline Multiparous & $738(64.5)$ & $1250(55.4)$ & $1.44(1.24$ to 1.67$)$ & \\
\hline Missing & $3(0.3)$ & $22(1.0)$ & $0.33(0.10$ to 1.12$)$ & \\
\hline \multicolumn{5}{|l|}{ Multiple pregnancy } \\
\hline No & $1083(94.7)$ & $2211(98.0)$ & 1.0 & 1.0 \\
\hline Yes & $59(5.2)$ & $27(1.2)$ & 4.46 (2.81 to 7.08$)$ & 3.88 (2.42 to 6.22 ) \\
\hline Missing & $2(0.2)$ & $18(0.8)$ & 0.23 (0.53 to 0.98) & 0.20 (0.02 to 2.54) \\
\hline \multicolumn{5}{|l|}{$\begin{array}{l}\text { Past pregnancy } \\
\text { conditions } \ddagger\end{array}$} \\
\hline No & $1041(91.0)$ & $2121(94.0)$ & 1.0 & 1.0 \\
\hline Yes & $94(8.2)$ & $104(4.6)$ & 1.81 (1.38 to 2.46$)$ & 1.58 (1.16 to 2.14$)$ \\
\hline Missing & $9(0.8)$ & $31(1.4)$ & $0.59(0.28$ to 1.25$)$ & $1.12(0.36$ to 3.54$)$ \\
\hline
\end{tabular}

${ }^{*}$ All variables adjusted for all other variables in the table.

†Cardiac disease, diabetes mellitus, epilepsy, essential hypertension, haematological disorders, past thrombotic event, recent/current anticoagulation, intravenous drug use and/or alcohol abuse.

$\ddagger$ Amniotic fluid embolism, gestational diabetes, pregnancy-induced hypertension, pre-eclampsia, eclampsia, thrombotic event, acute fatty liver of pregnancy, manual removal of placenta, placenta accreta, past classical caesarean section.

BMI, body mass index.

differences in health-seeking behaviour, or differences in access to, or provision and quality of services during pregnancy, delivery and the post-partum period.
In addition to finding an association between severe morbidity and factors such as pre-existing medical conditions, multiple pregnancy and past pregnancy 


\begin{tabular}{llllr}
\hline Table 4 Sensitivity analysis for missing observations & & & \\
\hline Missing values & Subcategory & Cases (\%) & Controls (\%) & Adjusted OR (95\% Cl) \\
\hline Socioeconomic group & & & & \\
Missing SEP values recoded to 'Managerial/ & Managerial & $485(42.4)$ & $870(38.6)$ & 1.0 \\
Professional' (best case) & Intermediate & $244(21.3)$ & $482(21.4)$ & $1.01(0.83$ to 1.23$)$ \\
& Routine/ & $273(23.9)$ & $595(26.4)$ & $0.99(0.82$ to 1.21$)$ \\
& manual & & & $1.02(0.79$ to 1.32$)$ \\
Missing SEP values recoded to 'unemployed' & Unemployed & $142(12.4)$ & $309(13.7)$ & 1.0 \\
(worst case) & Managerial & $292(25.5)$ & $567(25.1)$ & $1.17(0.94$ to 1.46) \\
& Intermediate & $244(21.3)$ & $482(21.37)$ & $1.17(0.94$ to 1.46) \\
& Routine/ & $273(23.9)$ & $595(26.4)$ & \\
& manual & & & \\
& Unemployed & $335(29.3)$ & $612(27.1)$ & $1.38(1.11$ to 1.72) \\
\hline
\end{tabular}

complications, this study also reflected the findings of past studies in France and the Netherlands ${ }^{6} 2632$ which have demonstrated a significantly increased risk of severe morbidity among women from minority ethnic groups. The suggested association with socioeconomic position was, however, independent of these associations.

\section{Implications of the study findings}

Health research in various settings worldwide has illuminated the ongoing existence of the 'inverse care law', first described in 1971 by Tudor Hart as the tendency for the 'availability of good medical care to vary inversely with the need for it in the population served'. 37

Since the global financial crisis in 2008, the WHO has stressed that "as standards of living decrease in many countries, and government revenues are tightened, (we would argue that) it is even more urgent that the distributional effects on all policies are taken into account in policy decision making." 38 In a paper that argues that social welfare spending is as important as protecting health through safeguarding the healthcare budget, Stuckler $e t a l^{39}$ have proposed that the economic crisis presents the opportunity to reorganise the provision of services to those most in need. Our findings identify one such group who may be in need.

'Maternity Matters' guidance for service commissioning in England released in 2007 emphasised the Government's commitment to providing choice guarantees for women regarding type of antenatal care and place of birth and also highlighted the need for future maternity services to address disproportionately higher rates of maternal morbidity among disadvantaged women. $^{40}$ Although it described a comprehensive approach to delivering improved maternity care, the guidance did not provide any specific recommendations as to how to improve services for women from socially disadvantaged backgrounds. Our study emphasises the need for developing such recommendations within the currently changing structure of health service commissioning in England.

\section{Strengths and limitations of the study}

UKOSS, the first system of its kind in obstetrics worldwide, has provided an invaluable wealth of information on uncommon but serious disorders of pregnancy. The active, negative surveillance approach has ensured robust case ascertainment, and many of the UKOSS studies are the largest-scale studies of rare disorders of pregnancy worldwide.

By studying disorders of pregnancy and childbirth in separate studies, UKOSS provided the means by which to explore 'severe maternal morbidity' due to direct pregnancy causes as an aggregate of multiple conditions, thereby avoiding the challenges encountered by previous studies which have used combined clinical and intervention criteria. It also avoids the perennial difficulty that there is no universally agreed definition of what constitutes 'severe maternal morbidity'. One disadvantage of this approach is that 'indirect causes' of maternal morbidity were excluded from our analysis, including several major contributors to maternal mortality in the UK such as cardiac disease, thromboembolic disease and puerperal psychosis/suicide. ${ }^{41}$

The design of UKOSS studies ensures that sampling bias is minimised by recruiting cases from all obstetric units across the UK, thus including women from all different ethnic, age and socioeconomic groups. Selection of controls is also aimed at attaining a representative sample of the general population of women giving birth by recruiting women from the same obstetric units as cases throughout the UK during the same time period. A comparison between UKOSS controls and national maternity data suggests that the controls recruited for UKOSS studies are closely representative of the general, child-bearing population. ${ }^{19}$

A universal challenge for studies that seek to explore the impact of social disadvantage in society is how to best capture the concept of 'social disadvantage' and define socioeconomic position. There are multiple dimensions to social disadvantage and there are many different approaches to defining a person's position in the social structure of society. The retrospective collection of data for UKOSS from patient records limited the definition of socioeconomic 
position to maternal occupation (or paternal where maternal was not available). Using the national classification of socioeconomic position (NS-SEC) ensured the study population was categorised using a system that is used nationally. However, the collection of other socioeconomic indicators such as level of education, years of schooling, residential location or income was not possible although this would have allowed further analysis of social disadvantage by using composite measures of disadvantage such as the Index of Multiple Deprivation. There is thus a place for further research using other indicators of socioeconomic position to see whether the results of this study are replicated.

The results of this study clearly apply only to high resource countries with well-developed healthcare systems. However, other high resource countries have different models of healthcare, such that pregnancy and delivery care may not be free at the point of access, as is the case in the UK. This study used only UK data and the results may therefore not be generalisable to women giving birth in other countries. Further research using information from other settings is therefore important to investigate whether socioeconomic position is associated with severe maternal morbidity in countries with differing health systems as this may give insights into the causes and where modifiable risks might lie. The use of data collected through the International Network of Obstetric Surveillance Systems, ${ }^{42}$ which use similar definitions and methodologies, may be a route to achieve this.

\section{CONCLUSIONS}

This study suggests that socioeconomic position may be associated with an increased risk of severe maternal morbidity, independent of risks associated with maternal age, ethnic group or known medical and pregnancy complications, although the association we observed was not statistically significant. However, the reasons for this possible association remain unclear, suggesting a need, not only to see if the observed association can be reproduced in other populations or settings, but also for further research to investigate whether there are differences in disease risks, lifestyle and health-seeking behaviour, access to care or the quality of care received by women from different socioeconomic groups. Further information about these differences would allow development of specific recommendations for the care of women from socially disadvantaged backgrounds in order to minimise future risks.

Contributors MK is the Director of the UKOSS research programme and JJK is the Director of the NPEU, under which UKOSS is carried out. As part of a $\mathrm{PhD}$ supervised by both JJK and MK, AL was the lead researcher for this project (performing data analysis and construction of all tables and figures) and prepared the initial draft of the manuscript. Both JJK and MK provided critical feedback and helped revise the text and tables included in the final paper. All authors read and approved the final manuscript.

Funding This article presents independent research commissioned by the National Institute for Health Research (NIHR) under the "Beyond maternal death: Improving the quality of maternity care through national studies of 'near-miss' maternal morbidity" programme (Programme Grant RP-PG-0608-10038). The views expressed in this publication are those of the author(s) and not necessarily those of the NHS, the NIHR or the Department of Health. AL was funded by a scholarship from the Rhodes Trust.

\section{Competing interests None.}

Provenance and peer review Not commissioned; externally peer reviewed.

Data sharing statement No additional data are available.

\section{REFERENCES}

1. Souza JP, Cecatti JG, Parpinelli MA, et al. Maternal morbidity and near miss in the community: findings from the 2006 Brazilian demographic health survey. Br J Obstet Gynaecol 2010;117:1586-92.

2. Souza JP, Cecatti JG, Faundes A, et al. Maternal near miss and maternal death in the World Health Organization's 2005 global survey on maternal and perinatal health. Bull World Health Organ 2010;88:113-19.

3. Office for National Statistics. Birth Statistics 2008 Series FM1 No.37. Newport: Office for National Statistics, 2010.

4. Waterstone M, Bewley S, Wolfe C. Incidence and predictors of severe obstetric morbidity: case-control study. BMJ 2001;322:1089-93; discussion 93-4.

5. Baskett TF. Epidemiology of obstetric critical care. Best Pract Res Clin Obstet Gynaecol 2008;22:763-74

6. van Roosmalen J, Zwart J. Severe acute maternal morbidity in high-income countries. Best Pract Res Clin Obstet Gynaecol 2009;23:297-304.

7. Bouvier-Colle MH, Varnoux N, Salanave B, et al. Case-control study of risk factors for obstetric patients' admission to intensive care units. Eur J Obstet Gynaecol Reprod Biol 1997;74:173-7.

8. Hardy JM, Azarowicz EN, Mannini A, et al. The effect of Asian influenza on the outcome of pregnancy, Baltimore, 1957-1958. Am J Public Health Nations Health 1961;51:1182-8.

9. Knight M, Kurinczuk JJ, Spark P, et al. Inequalities in maternal health: national cohort study of ethnic variation in severe maternal morbidities. BMJ 2009;338:b542.

10. Lewis G. Saving Mothers' Lives: reviewing maternal deaths to make motherhood safer: 2006-2008. Br J Obstet Gynaecol 2011;118 (Supp 1):1-203.

11. Kayem G, Kurinczuk J, Lewis G, et al. Risk factors for progression from severe maternal morbidity to death: a national cohort study. PLOS ONE 2011;6:e29077.

12. Pollock W, King JF. Inequalities in maternal health. BMJ 2009;338: b357.

13. Adler NE, Boyce WT, Chesney MA, et al. Socioeconomic inequalities in health. No easy solution. J Am Med Assoc 1993;269:3140-5

14. Knight M, Kurinczuk JJ, Tuffnell D, et al. The UK Obstetric Surveillance System for rare disorders of pregnancy. Br J Obstet Gynaecol 2005;112:263-5.

15. Knight M. Eclampsia in the United Kingdom 2005. Br J Obstet Gynaecol 2007;114:1072-8.

16. Knight $M$, Berg $C$, Brocklehurst $P$, et al. Amniotic fluid embolism incidence, risk factors and outcomes: a review and recommendations. BMC Pregnancy Childbirth 2012;12:7.

17. Knight M, Kurinczuk JJ, Spark $P$, et al. Cesarean delivery and peripartum hysterectomy. Obstet Gynecol 2008;111:97-105.

18. Knight M, Nelson-Piercy $\mathrm{C}$, Kurinczuk JJ, et al. A prospective national study of acute fatty liver of pregnancy in the UK. BMJ 2008;57:951-6.

19. Knight $M$, Tuffnell $D$, Brocklehurst $P$, et al. Incidence and risk factors for amniotic-fluid embolism. Obstet Gynecol 2010;115:910-17.

20. Knight M. Peripartum hysterectomy in the UK: management and outcomes of the associated haemorrhage. Br J Obstet Gynaecol 2007;114:1380-7.

21. Fitzpatrick KE, Kurinczuk JJ, Alfirevic Z, et al. Uterine rupture by intended mode of delivery in the UK: a national case-control study. PLoS Med 2012;9:e1001184.

22. Gray $R$, Hollowell J, Brocklehurst $P$, et al. Inequalities in infant mortality project briefing paper 2. In: R G, ed. Health inequalities infant mortality target: technical background. Oxford: National Perinatal Epidemiology Unit, 2009.

23. Knight M, Kurinczuk JJ, Spark $P$, et al. Inequalities in maternal health: national cohort study of ethnic variation in severe maternal morbidities. BMJ 2009;338:b542.

24. Baskett TF, O'Connell CM. Severe obstetric maternal morbidity: a 15-year population-based study. J Obstet Gynaecol 2005;25:7-9. 
25. Zwart JJ, Richters A, Ory F, et al. Eclampsia in the Netherlands. Obstet Gynaecol 2008;112:820-7.

26. Zwart JJ, Richters JM, Ory F, et al. Severe maternal morbidity during pregnancy, delivery and puerperium in the Netherlands: a nationwide population-based study of 371000 pregnancies. $\mathrm{Br} \mathrm{J}$ Obstet Gynaecol 2008;115:842-50.

27. Zhang $\mathrm{WH}$, Alexander S, Bouvier-Colle $\mathrm{MH}$, et al. Incidence of severe pre-eclampsia, postpartum haemorrhage and sepsis as a surrogate marker for severe maternal morbidity in a European population-based study: the MOMS-B survey. Br J Obstet Gynaecol 2005;112:89-96.

28. Waterstone $\mathrm{M}$, Bewley S, Wolfe $\mathrm{C}$. Incidence and predictors of severe obstetric morbidity: case-control study. $B M J$ 2001;322:1089-93; discussion 93-4.

29. Wen SW, Huang L, Liston $R$, et al. Severe maternal morbidity in Canada, 1991-2001. Can Med Assoc J 2005;173:759-64.

30. Siega-Riz AM, Laraia B. The implications of maternal overweight and obesity on the course of pregnancy and birth outcomes. Maternal ChildHealth J 2006;10:S153-6.

31. Roberts CL, Ford JB, Algert CS, et al. Trends in adverse maternal outcomes during childbirth: a population-based study of severe maternal morbidity. BMC Pregnancy Childbirth 2009;9:1-10.

32. Philibert M, Deneux-Tharaux C, Bouvier-Colle MH. Can excess maternal mortality among women of foreign nationality be explained by suboptimal obstetric care? Br J Obstet Gynaecol 2008;115:1411-18.
33. Perlow JH, Morgan MA. Massive maternal obesity and perioperative cesarean morbidity. Am J Obstet Gynecol 1994;

170:560-5.

34. Cedergren MI. Maternal morbid obesity and the risk of adverse pregnancy outcome. Obstet Gynaecol 2004;103:219-24.

35. Al-Zirqi I, Vangen S, Forsen $\mathrm{L}$, et al. Prevalence and risk factors of severe obstetric haemorrhage. Br J Obstet Gynaecol 2008;115:1265-72.

36. Zwart JJ, Jonkers MD, Richters A, et al. Ethnic disparity in severe acute maternal morbidity: a nationwide cohort study in the Netherlands. Eur J Public Health 2011;21:229-34.

37. Hart JT. The inverse care law. Lancet 1971;1:405-12.

38. Marmot M, Allen J, Bell R, et al. Building of the global movement for health equity: from Santiago to Rio and beyond. Lancet 2012;379:181-8.

39. Stuckler D, Basu S, McKee M. Budget crises, health, and social welfare programmes. BMJ 2010;340:c3311.

40. British Department of Health. Maternity matters: choice, access and continuity of care in a safe service. . London: Department of Health, 2007:56.

41. Cantwell R, Clutton-Brock T, Cooper G, et al. Saving Mothers' Lives: reviewing maternal deaths to make motherhood safer: 2006-2008. The Eighth Report of the Confidential Enquiries into Maternal Deaths in the United Kingdom. BJOG 2011;118(Suppl 1):1-203.

42. National Perinatal Epidemiology Unit. www.npeu.ox.ac.uk/inoss 


\section{Correction}

Lindquist A, Knight M, Kurinczuk JJ. Variation in severe maternal morbidity according to socioeconomic position: a UK national case-control study. BMJ Open 2013;3:e002742. The order of author names is incorrect. It should be Lindquist A, Kurinczuk JJ, Knight M.

BMJ Open 2013;3:e002742corr1. doi:10.1136/bmjopen-2013-002742corr1 